\title{
Sanitary condition and its microbiological quality of improved water sources in the Southern Region of Ethiopia
}

\author{
Tsigereda Assefa Alemayehu • Abel Weldetinsae • Daniel Abera Dinssa • Firehiwot Abera \\ Derra • Tesfaye Legese Bedada • Yosef Beyene Asefa • Sisay Derso Mengesha $\cdot$ Zinabu \\ Assefa Alemu • Melaku Gizaw Serte • Kirubel Tesfaye Teklu • Mesay Getachew \\ Woldegabriel • Moa Abate Kenea • Harold van den Berg • Ana Maria de Roda Husman
}

Received: 15 October 2019/Accepted: 14 April 2020 / Published online: 30 April 2020

(C) The Author(s) 2020

\begin{abstract}
In the Southern Nations, Nationalities, and Peoples' Region of Ethiopia, improved water is the main source of water for household purposes. Access to improved water closer to their homes benefits the community in many ways. It improves their health status, saves their time and energy, and improves their productivity in jobs and education they are engaged in. However, due to natural and human activities, improved water sources do not always deliver good quality of
\end{abstract}

T. A. Alemayehu $(\bowtie) \cdot A$. Weldetinsae $\cdot$ D. A. Dinssa

F. A. Derra - T. L. Bedada • Y. B. Asefa - S. D. Mengesha •

Z. A. Alemu • M. G. Serte $\cdot$ K. T. Teklu •

M. G. Woldegabriel • M. A. Kenea

Ethiopian Public Health Institute, Addis Ababa, Ethiopia

e-mail: tsigeredaalem7@gmail.com

A. Weldetinsae

e-mail: abelweldetinsae@gmail.com

D. A. Dinssa

e-mail: daniel.aberad@gmail.com

F. A. Derra

e-mail: firehiwot_a@yahoo.com

T. L. Bedada

e-mail: tesfayelegesse21@gmail.com

Y. B. Asefa

e-mail: yosef_beyene@yahoo.com

S. D. Mengesha

e-mail: sisaydrs2@gmail.com water. It can be contaminated by different pathogenic microorganisms and chemicals. The result indicated that $44.7 \%$ and $50.9 \%$ of the samples were contaminated with Escherichia coli and enterococci respectively, and from the sanitary condition survey, $57.6 \%$ of the water sources exhibited from intermediate- to very high-risk level. And the risk priority matrix identifies 95 (27.9\%) samples with high risk and $54(15.9 \%)$ of the samples with very high risk. The main risks identified at those

\section{Z. A. Alemu}

e-mail: zinabuassefa@gmail.com

M. G. Serte

e-mail: melakugizaw@gmail.com

K. T. Teklu

e-mail: getkirub@gmail.com

M. G. Woldegabriel

e-mail: johnny.woldegabriel04@gmail.com

M. A. Kenea

e-mail: moaabate@gmail.com

H. van den Berg $\cdot$ A. M. de Roda Husman

National Institute for Public Health and the Environment,

Bilthoven, The Netherlands

H. van den Berg

e-mail: harold.van.den.berg@rivm.nl

A. M. de Roda Husman

e-mail: ana.maria.de.roda.husman@rivm.nl 
unsafe water sources were that the drainage canals were blocked with mud, grass, leaves, and stones; animals drinking the overflow water and grazing in the proximity of water sources and feces such as cow dung were observed; inadequate protection of water sources such as absence of fences and diversion ditches; and stagnant water near the source. The study conducted in the Southern Nations, Nationalities, and Peoples' Region has clearly indicated that people may be at risk of being exposed to pathogens in half of the improved water sources when used for drinking based on the microbial indicator data or the sanitary inspection risk score. Though no correlation resulted from water quality and sanitary condition of sources, the risk priority matrix did enable prioritization of 54 very high-risk-level water sources for urgent targeted interventions from a total of 340 improved drinking water sources. From this, targeted interventions, improving water management practices, identifying and implementing effective water treatment options, providing sustainable energy sources for the supply of continuous water, and implementing climate resilience water safety planning, are recommended.

Keywords E. coli $\cdot$ Enterococci $\cdot$ Risk priority matrix

$\begin{array}{ll}\text { Abbreviations } \\ \text { BH } & \text { Borehole } \\ \text { CS } & \text { Caped spring } \\ \text { CFU } & \text { Colony-forming units } \\ \text { E. coli } & \text { Escherichia coli } \\ \text { ISO } & \text { International Standard Organization } \\ \text { SDG } & \text { Sustainable development goal } \\ \text { SNNPR } & \begin{array}{l}\text { Southern Nations, Nationalities, and } \\ \text { Peoples' Region }\end{array} \\ \text { SW } & \text { Shallow well } \\ \text { UNICEF } & \text { United Nations Children's Fund } \\ \text { WHO } & \text { World Health Organization }\end{array}$

\section{Background}

Worldwide, 159 million people in 2015 still collect drinking water directly from surface water sources, of whom 58\% lived in sub-Saharan Africa (WHO/ UNICEF 2017). In many low-income countries including those in Africa, it may be difficult to deliver tap water to each and every household in rural areas. The development of water infrastructure is very expensive because fewer people are serviced over large distance of piping. Opting for improved water supplies has been at the attention of Ethiopian Government because it benefits the community in many ways, such as access to water closer to their homes which improves their health status, saves their time and energy, and improves their productivity in jobs and education they are engaged in. The present improved water sources may not always deliver good quality of water. It can be contaminated by chemicals and pathogenic microorganisms.

In Ethiopia, about $75 \%$ of health problem is communicable disease associated with unsafe and inadequate water and poor human excreta disposal (Tabor et al. 2011). Waterborne infectious diseases are caused by a variety of microbial agents such as viruses, bacteria, protozoa, and helminths. Some of the diseases associated with those agents include cholera, gastroenteritis, infectious hepatitis, diarrhea, typhoid fever, giardiasis, poliomyelitis, and ascariasis (Ashbolt 2004). Cholera is one of the worst waterborne diseases caused by the bacterium Vibriocholerae, responsible for acute watery diarrhea and lead to illness and death to human beings in many parts of the world. In June 2006, in Oromia region of Ethiopia, the outbreak of acute watery diarrhea was reported, resulting in more than 1900 cases in midSeptember (Bartels et al. 2010). This disease spread to the different Ethiopian regions of Amhara, Tigray, and Southern Nations, Nationalities, Peoples' Region (SNNPR) (Bartels et al. 2010). Since that time, this disease relapses every year especially in the rainy season and continues to be public health concern.

Studies indicate that improper management of drinking water sources, such as inadequate maintenance, poor sanitary practice, and improper site selection are the major factors that lead to the contamination of drinking water. A water quality monitoring performed by Howard et al. (2003a) in Uganda on ground water justified that the concentration of thermotolerant and fecal streptococci increased in the rainy season due to poor construction of wellheads and sanitary seals, inadequate fences, and erosion of backfill area. Lack of appropriate management of human excreta disposal system is another route for the entrance of pathogenic microorganisms into ground and surface water (Howard et al., 2003a). Ground water can be contaminated by fecal matter drawn from the underlying aquifer (Graham \& Polizzotto 2013). It is supported by the study conducted in Marondera district, Zimbabwe, by 
Dzwairo et al. (2006) showing that ground water is contaminated by total and fecal coliforms due to leach of contaminants from pit latrines. Agricultural activities are also another source of water pollution. Manure applied to land as a fertilizer can be washed away from farm fields during the rainy season and join the water sources which can serve as microbial contaminant.

In the Southern Region of Ethiopia, drinking water is obtained from improved sources such as caped springs, protected shallow wells, and boreholes. Studies have shown that water quality in this region is more deprived compared with that in other parts of Ethiopia. Rapid water quality assessment was performed by Tadesse et al. (2010) on improved water sources from 2004 to 2005; the SNNPR water sources had the lowest microbial water quality than other regions of Ethiopia. From that time to present, there is no organized water quality assessment that can cover most areas of this region. Therefore, the main objectives of this survey were to assess the quality of water and factors that contributes to the contamination of water and to identify the water sources that are at higher risk and priorities that need intervention.

\section{Materials and methods}

Study area

SNNPR (Fig. 1) is one of the nine regions in Ethiopia and lies in the southern part of the country. It is the largest region covering an area of $112,323.19 \mathrm{~km}^{2}$. It lies between 40.43-80.58 North latitude and 340.88-390.14 East longitude. The elevation ranges from 376 to 4 , $207 \mathrm{~m}$ above sea level. It is bordered by national boundaries in the North-West Gambela Regional state and surrounded by Oromiya Regional State in the NorthEast directions. It extends its boundaries to Kenya in the South and the Republic of Sudan in the South-West. About $56 \%$ of the total area of the state is found below $1500-\mathrm{m}$ elevation, which is categorized largely as hottest low land. The rest $44 \%$ is found in the temperate climatic zone. The rainfall intensity and duration varies from place to place within the region. It decreases from West and North-West to South-Eastwards. The mean annual rainfall ranged from 400 to $2200 \mathrm{~mm}$, mainly in the months of February to March. Of the regional population, $90 \%$ engage in farming and pastoral system.
Sampling design

The survey was conducted from October 2014 to June 2015. It was carried out by taking water samples and at the same time performing visual inspection of the sanitary condition of the water source, the so-called sanitary inspection (WHO 2012). The water samples for the study purposes were taken from improved water sources including boreholes, caped springs, and protected shallow wells. The community used these water sources for drinking and other household purposes. Sampling sites were selected based on a stratified random sampling method described by Howard et al. (2003a). The sampling covered all different geographical areas and climate conditions in SNNPR. This survey assessed the sanitary condition of water sources and the microbial water quality. During sample collection, it was attempted to collect additional data related to the water quality and sanitary inspection including if the water is treated from the source and the type of treatment practiced.

\section{Microbial analysis}

Microbial water quality was assessed by analyzing indicator bacteria $E$. coli and enterococci. These bacteria are regarded as the most common and reliable microbial indicators exclusively fecal in origin that shows contamination of water with fecal matter (Howard et al., 2003a). Enterococci have been used to augment testing for $E$. coli because most of the enterococci species are also fecal in origin and survive longer than E. coli (WHO 2008). For the purpose of bacterial analyses, water samples were collected by sterilized glass bottles placed in an ice-packed container to maintain the temperature around $4{ }^{\circ} \mathrm{C}$ and transported to the nearest zonal public health laboratories. All samples were analyzed within $12 \mathrm{~h}$ of collection and colony-forming units of $E$. coli and enterococci. It was enumerated by taking 100-ml aliquots of the water sample based on Ethiopian Standard Methods ES ISO 9308-1:2001 and ES ISO 7899-2:2005 respectively.

\section{Sanitary inspection}

Sanitary inspection was performed during water sample collection for each sampling site by following standard format described by WHO (2012). Different sanitary inspection forms representing three types of water 


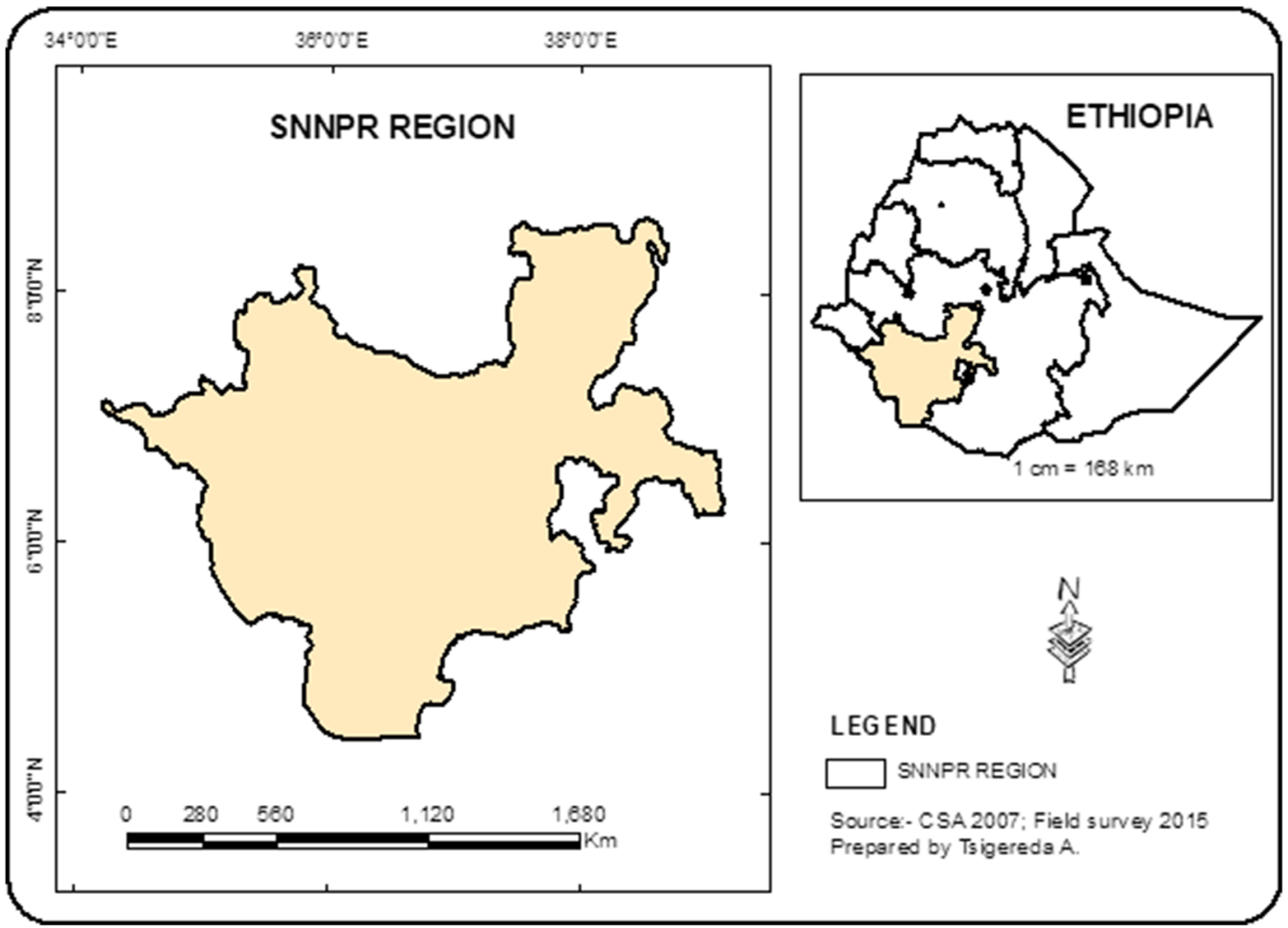

Fig. 1 Map of SNNPR

sources, borehole, caped spring, and protected shallow wells, were prepared. These forms consist of a set of questions with "yes" or "no' answers to help in finding the most important factors that contribute to the contamination of water. Some of the questions indicate structural deficiencies in the construction of concrete walls, distance between the water source and latrine, and proper fencing to avoid the entrance of animals and people closer to the water source. The number of "yes" answers indicates risk of the entry of contaminants into the water source and the number of "no" answers indicates no or negligible risk of contamination of the given water source. By summing all "yes" answers in the given filled form, the total number of risks of contamination was obtained at 0 to 10 score scale. Answers were reevaluated into different risk categories as low, intermediate, high, and very high risk.

Combined sanitary inspection and water quality analysis

To find out water sources that need more attention and to give priorities for the intervention, a risk priority matrix was prepared by coupling sanitary condition survey with water quality test results. The risk assessment and the recommended remedial action prioritization are based on the microbiological load level and sanitary inspection risk score.

Data analysis

IBM SPSS 20 for windows software was used to analyze descriptive statistics such as percentages, ranges, geometric mean, and frequency. To find if there is any significant association between sanitary risk score and microbial contamination of the water, Spearman's rank correlation was applied.

\section{Results}

A total of 340 water samples were collected of which 88 from boreholes, 130 from caped springs, and 122 from protected shallow wells. The result of microbial analysis and sanitary inspection of the water source is presented in terms of percentages of water samples in Tables 1 and 2 . And risk priority matrix by coupling water quality and sanitary inspection is presented in Table 3 . 
Table 1 Percentage (\%) of water samples contaminated with $E$. coli and/or enterococci by water source type

\begin{tabular}{|c|c|c|c|c|c|c|}
\hline \multirow[t]{2}{*}{ Indicator organisms } & & \multicolumn{5}{|c|}{ Risk categories and their respective bacterial load in $\mathrm{CFU} / \mathrm{ml}$ of water } \\
\hline & & No risk & Low risk & Intermediate risk & High risk & Very high risk \\
\hline \multirow[t]{6}{*}{ E. coli } & Water source & $<1$ & $1-10$ & $10-100$ & $100-1000$ & $>1000$ \\
\hline & & No $(\%)$ & No $(\%)$ & No $(\%)$ & No $(\%)$ & No $(\%)$ \\
\hline & $\mathrm{BH}$ & $53(60.2)$ & $10(11.4)$ & $14(15.9)$ & $7(8)$ & $4(4.5)$ \\
\hline & $\mathrm{CS}$ & $60(46.1)$ & $20(15.4)$ & $27(20.8)$ & $14(10.8)$ & $9(6.9)$ \\
\hline & SW & $75(61.5)$ & $12(9.8)$ & $18(14.8)$ & $13(10.6)$ & $4(3.3)$ \\
\hline & Total & $188(55.3)$ & $42(12.4)$ & $59(17.4)$ & $34(10)$ & $17(5)$ \\
\hline \multirow[t]{4}{*}{ Enterococci } & $\mathrm{BH}$ & $51(58)$ & $16(18.2)$ & $12(13.6)$ & $9(10.2)$ & $0(0.0)$ \\
\hline & $\mathrm{CS}$ & $46(35.4)$ & $33(25.4)$ & $27(20.7)$ & $20(15.4)$ & $4(3.1)$ \\
\hline & SW & $70(57.4)$ & $22(18.0)$ & $19(15.6)$ & $10(8.2)$ & $1(0.8)$ \\
\hline & Total & $167(49.1)$ & $71(20.9)$ & $58(17.1)$ & 39 (11.5) & $5(1.5)$ \\
\hline
\end{tabular}

$B H$ borehole, $C S$ caped spring, $S W$ shallow well

Microbial water quality

All 340 water samples collected were analyzed for the indicator organisms $E$. coli and enterococci. The water quality analysis result for improved water source (boreholes, protected shallow wells, and caped springs) is summarized according to percentage of water samples and their microbial load in Table 1. The microbial load was characterized into different categories based on the risk levels. Samples with E. coli and/or enterococci < $1 \mathrm{CFU} / 100 \mathrm{ml}$ are in conformity with WHO guideline, 1-10 CFU/100 ml with low risk, $10-100 \mathrm{CFU} / 100 \mathrm{ml}$ with intermediate risk, 100-1000 with high risk, and > $1000 \mathrm{CFU} / 100 \mathrm{ml}$ with very high risk (WHO, 2012). For the simplicity of interpretation of results, the risk level of enterococci was also categorized as E. coli.

Table 2 Sanitary inspection risk score for each type of water source

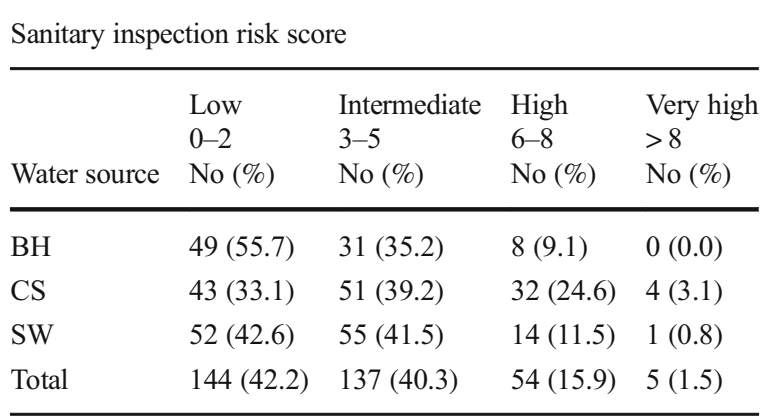

$B H$ borehole, $C S$ caped spring, $S W$ shallow well
The density of E. coli and enterococci differs greatly among sources from a minimum of 0 to a maximum of 7500 and $9876 \mathrm{CFU} / 100 \mathrm{~mL}$, respectively. Of the 340 water samples for all combined water sources, $188(55.3 \%)$ samples for E. coli and $167(49.1 \%)$ for enterococci complied with the WHO guideline (0 CFU/100 ml). However, 152 $(44.7 \%)$ and $173(50.9 \%)$ of the samples were contaminated with $E$. coli and/or enterococci respectively, at different levels of contamination. Of the contaminated samples, $152(44.7 \%)$ were positive for both $E$. coli and enterococci while $21(6.2 \%)$ of the sources contained enterococci only.

The water quality differences by water source types according to the microbial risk level of E. coli and enterococci for boreholes, caped springs, and protected shallow wells are shown also in Table 1. More than half, i.e., $53(60.2 \%)$, of the samples taken from boreholes were at the level with no risk of contamination E. coli< $1 \mathrm{CFU} / 100 \mathrm{ml}$. The remaining $35(39.8 \%)$ samples were at low- to intermediate-risk levels and $11(12.5 \%)$ at high and very high risk of contamination. From caped spring sources, more than $50 \%$ of the samples did not comply with WHO guideline value. Most of the samples $27(20.7 \%)$ were at intermediate risk of $E$. coli from 10 to $100 \mathrm{CFU} / 100 \mathrm{ml}$. Out of the shallow wells, 75 $(61.5 \%)$ met the WHO guideline value with no risk of contamination. The remaining $38.5 \%$ of the samples verified from low to very high risk. The more frequent value was $18(14.7 \%)$ at intermediate level of contamination. 
Table 3 Risk priority matrix adapted from (WHO, 2012)

\begin{tabular}{|c|c|c|c|c|c|c|c|c|c|c|c|c|c|c|c|c|}
\hline E.Coli & \multicolumn{4}{|c|}{ SW } & \multicolumn{4}{|c|}{ CS } & \multicolumn{4}{|c|}{$\mathrm{BH}$} & \multicolumn{4}{|c|}{ Total } \\
\hline $\mathrm{CFU} / 100 \mathrm{ml}$ & $0-2$ & $3-5$ & $6-8$ & $9-10$ & $0-2$ & $3-5$ & $6-8$ & $9-10$ & $0-2$ & $3-5$ & $6-8$ & $9-10$ & $0-2$ & $3-5$ & $6-8$ & $9-10$ \\
\hline$<1$ & 28 & 38 & 8 & 1 & 18 & 28 & 13 & 1 & 27 & 19 & 7 & 0 & 73 & 85 & 28 & 2 \\
\hline $1-10$ & 8 & 2 & 2 & 0 & 7 & 6 & 6 & 1 & 8 & 2 & 0 & 0 & 23 & 10 & 8 & 1 \\
\hline $11-100$ & 7 & 8 & 3 & 0 & 10 & 10 & 7 & 0 & 7 & 6 & 1 & 0 & 24 & 24 & 11 & 0 \\
\hline$>100$ & 9 & 7 & 1 & 0 & 8 & 7 & 6 & 2 & 7 & 4 & $\overline{0}$ & 0 & 24 & 18 & 7 & 2 \\
\hline
\end{tabular}

$\mathrm{BH}=$ Borehole, $\mathrm{CS}=$ Caped Spring, $\mathrm{SW}=$ Shallow well

\section{Legend}

\begin{tabular}{|l|l|l|l|l|}
\hline Risk level & Low risk & Intermediate risk & High risk & Very high risk \\
\hline
\end{tabular}

Of 88 boreholes, in 51 (58\%) of the samples, enterococci were not detected in $100 \mathrm{ml}$. The contamination level differed per borehole, 28 (31.8\%) of the water samples were at low- and intermediate-risk level, whereas $9(10.2 \%)$ of the samples were at high-risk level. Very high risk (>1000 count/100 ml) of enterococci was not observed for borehole samples. From caped spring sources, only $46(35.4 \%)$ of the samples were enterococci free. Higher incompliance was observed in this source; $84(64.6 \%)$ were contaminated with enterococci at different microbial risk levels, $60(46.2 \%)$ were at low- and intermediate-risk, and 24 (18.4\%) of the samples were at high- and very high-risk levels. From 122 protected shallow well samples analyzed, 70 (57.4\%) were negative for enterococci, $41(33.6 \%)$ of the samples were at low and intermediate risk while $11(9 \%)$ were at high and very high risk.

\section{Sanitary inspection}

The results observed from sanitary inspection of 340 sites were evaluated in different risk levels summarized in Table 2. Based on WHO guideline, it is considered low if the risk score is between 0 and 2 ; intermediate risk, 3 and 5; high risk, 6 and 8; and very high risk, greater than 8 . From all types of water sources, 144 (42.4\%) samples scored a low-risk level, whereas 137 (40.3\%) scored an intermediate-risk, 54 (15.9\%) a highrisk, and $5(1.5 \%)$ a very high-risk level. The main risks identified at those unsafe water sources were that:
- the drainage canals were blocked with mud, grass, leaves, and stones;

- animals drinking the overflow water and grazing in the proximity of water sources;

- inadequate protection of water sources such as absence of fences and diversion ditches;

- stagnant water near the source;

- construction of latrines close to water source at less than 30-m radius and located upstream;

- Animal feces such as cow dung were observed inside the fence. Mostly, residents bring their animals to the water sources for drinking, and donkeys and horses are also taken to transport water, while posing risks of contamination.

To verify any correlation between $E$. coli and enterococci contamination with the sanitary inspection score, Spearman's rank correlations were calculated. The sanitary score for each water source type and also for all combined sources did not correlate with microbial quality of water.

Combined sanitary inspection and water quality result

The combined analysis of water quality data of $E$. coli with a sanitary inspection risk score, the so-called risk priority matrix (WHO 2012), was calculated for different water source types and presented in Table 3 . The risk priority matrix showed that only $73(21.5 \%)$ of the water sources were at low risk. The remaining sources were at 
risks from intermediate- to very high-risk level. One hundred eighteen $(34.7 \%)$ of the samples were at an intermediate risk, $95(27.9 \%)$ at high risk, and 54 $(15.9 \%)$ of the samples were at very high risk. From those different water source types categorized as high and very high risk, 32 (9.4\%) were boreholes, 46 $(13.5 \%)$ were protected shallow wells, and 71 (20.9\%) were caped springs.

\section{Discussion}

Improved water sources are drinking water sources that are protected from the outside environment by concrete covers (WHO/UNICEF 2017). Improved sources include piped water, boreholes or tube wells, protected dug wells, caped springs, and packaged or delivered water (WHO/UNICEF 2017). It is believed that these water sources are safer compared to unimproved sources such as open wells and surface water. However, it is untrue that all improved sources are safe for drinking and other household purposes. The microbial water quality analyses showed that $45 \%$ of water samples taken from improved water sources were contaminated with $E$. coli and $51 \%$ of water samples were contaminated enterococci. This result is in agreement with Tadesse et al. (2010) who performed a rapid water quality assessment in Ethiopia from 2004 to 2005 and indicated that only $58.6 \%$ improved water sources respect the WHO guideline value for total coliform bacteria. In Dire Dawa City Administrative Council, Ethiopia, a bacteriological water quality analysis was conducted by Amenu et al. (2012) from protected springs and wells, and the result demonstrates that $85 \%$ of water samples taken were positive for indicator bacteria. In the Dominican Republic, the assessment of microbial quality of improved drinking water showed that the quality of water was poor with more than $90 \%$ of the water samples contaminated with E. coli bacteria and $47 \%$ of samples were having high and very high sanitary risk to human health (Baum et al., 2014).

Different reasons can be presented to justify the reason for the contamination of improved water sources in this study. In the SNNPR, the water supply from shallow wells and boreholes was not continuous; water was only collected in the morning and evening for two reasons. The first reason was that in the arid and semi-arid areas of the country, the water yield is minimal. To avoid the shortage of water, residents abstract water at a fixed time of the day especially in the dry season. The second reason is that motorized water sources function by diesel and electric power for the pumping of water from the ground. When there is interruption of electricity, water supply will be disrupted for unlimited hours in a day. This intermittent supply of water may lead to the contamination of water due to re-growth and multiplication of microbes. Besides, when water stays at a static condition and under negative pressure, microorganisms may be drawn from the surrounding environment into the water source (Ayoub, 2006). Tokajian and Hashwa (2003) confirmed in their study that drinking water quality was compromised due to re-growth of microorganisms associated with intermittent supply of water in Lebanon and could occur in the SNNPR.

The sanitary inspection score for each water source type and also for all combined sources did not correlate with microbial quality of water. This study agrees with Luby et al. (2008) and indicates that the sanitary condition does not necessarily predict the microbial quality of water and it is an indication that other routes of contamination of water sources are more important. On the other hand, our study contradicts with the investigation performed by Howard et al. (2003b) who showed a strong correlation between sanitary score and the presence of thermotolerant coliforms in spring water samples; this contradictory result may be due to the study period which coincided with the rainy season, whereas in our survey, most of our studies were conducted in the dry season. Emphasis has been given to seasonal variations on microbial contamination of water sources by different researchers. Godfrey et al. (2005) confirmed that the microbial concentration of water increased in rainy season than in the dry season. In this season, water sources can be contaminated through poorly maintained infrastructure as rain water collects pollutants while it runs off farms, streets, and waste disposal areas. In dry season, in most areas of the southern region, more droughts are expected so that this method may be replaced by a better method which suites the dry season.

From the sanitary inspections, one of the risks identified in the area was the closeness of pit latrines 
to the water sources (less than $30 \mathrm{~m}$ ) situated uphill from the water source. In this situation, contaminants can be transported to the groundwater through fractured aquifers in the subsurface due to openings and cracks in the soil and rock (Graham \& Polizzotto 2013).

From the three water source types, protected springs were more highly contaminated than boreholes and shallow wells. This result is in agreement with Tadesse et al. (2010); the water quality survey performed on improved water sources in different regions of Ethiopia indicated that spring water sources were more contaminated by total coliform bacteria in the SNNPR. This may be due to less effectiveness of the water treatment method. Because all spring water sources have no tap, the water flows continuously and very quickly. The added chlorine will be immediately washed away; it has no enough contact time to kill microorganisms in the water. On the contrary, chlorine introduction to boreholes and shallow wells has enough contact time for disinfection and therefore, the water will be welltreated before being pumped out and distributed to consumers.

\section{Conclusion}

The study conducted in the Southern Nations, Nationalities, and Peoples' Region has clearly indicated that people may be at risk of being exposed to pathogens in half of the improved water sources when used for drinking based on the microbial indicator data or the sanitary inspection risk score.

Though no correlation resulted from the water quality and sanitary condition of sources, risk priority matrix did enable prioritization of 54 very highrisk-level water sources for targeted interventions from a total of 340 improved drinking water sources. However, the survey was performed and sources only sampled once and such a study could be repeated to inform decision makers of progress. Moreover, most of the samples were collected in the dry season explaining the absence of the sought correlation. It is very apparent that the rainy season has more impact on the quality of water due to water movement with a possibility of ingression of contaminants into the water sources. To ensure comprehensive results, it is very appropriate to extend the study to surveying the water sources in the rainy season and more frequent analysis of the microbial water quality. Moreover, strengthening of water supply management could be further improved by socalled climate resilient water safety planning.

From this, targeted interventions could be recommended, such as improving the construction of water sources, safeguarding the water sources by preventing animals, flood, and any contaminants entering in to the facilities, identifying and implementing effective water treatment options, providing sustainable energy sources for the supply of continuous water, and establishing national water quality surveillance and monitoring systems to verify that the water being supplied to the consumer remains to be safe and adequate all the time. Those interventions can help to prevent diarrheal diseases such as cholera from relapsing in the country every year.

Availability of data and material The datasets generated and/ or analyzed during the current study are not publicly available because the data are owned by Ethiopian Public Health Institute and upon permission from the institute can be available from the corresponding author on reasonable request.

Authors' contributions Tsigereda Assedfa Alemayehu: corresponding author, proposal development, sample collection, analysis, data analysis, and manuscript writing. Abel w/Tinsae Kidane: contribute during research design, sample collection and analysis, report writing. Daniel Abera Dinssa: sampling, laboratory analysis and data analysis. Firehiwot Abera Derra: laboratory analysis and edit manuscript. Tesfaye Legese Bedada: laboratory analysis and edit manuscript. Yosef Beyene Asefa: laboratory analysis and edit manuscript. Sisay Derso Mengesha: sample collection analysis data interpretation and manuscript review. Zinabu Assefa Alemu: sample collection analysis data interpretation manuscript review. Melaku Gizaw Serte: sample collection, analysis, data interpretation and manuscript review. Kirubel Tesfaye Teklu: sample collection, analysis, data interpretation and manuscript review. Mesay Getachew Woldegabriel: data analysis and manuscript review. Moa Abate Kenea: data analysis and manuscript review. Harold van den Berg: interpret datae, manuscript review, and editing. Ana Maria de Roda Husman: interpret data, manuscript review, and editing.

Funding information Ethiopian Public Health Institute is a source of funding for this research. The institute also provides cars for field investigation and sample collection and allocates human resources that collect samples and analyze collected samples in the laboratory.

\section{Compliance with ethical standards}

Competing interests The authors declare that they have no competing interests. 
Open Access This article is licensed under a Creative Commons Attribution 4.0 International License, which permits use, sharing, adaptation, distribution and reproduction in any medium or format, as long as you give appropriate credit to the original author(s) and the source, provide a link to the Creative Commons licence, and indicate if changes were made. The images or other third party material in this article are included in the article's Creative Commons licence, unless indicated otherwise in a credit line to the material. If material is not included in the article's Creative Commons licence and your intended use is not permitted by statutory regulation or exceeds the permitted use, you will need to obtain permission directly from the copyright holder. To view a copy of this licence, visit http://creativecommons.org/licenses/by/4.0/.

\section{References}

Ashbolt, N. J. (2004). Microbial contamination of drinking water and disease outcomes in developing regions. Toxicology, 198, 229-238.

Amenu, D., Menkir, S., \& Gobena, T. (2012). Microbiological quality of drinking water sources in rural communities of Dire Dawa Administrative Council. Science, Technology and Arts Journal, 1(4), 33-37.

Ayoub, G. M. (2006). Impact of intermittent water supply on water quality in Lebanon. International Journal of Environment and Pollution, 26(4), 379-397.

Bartels, S. A., Greenough, G. P., Tamar, M., \& VanRooyen, M. J. (2010). Investigation of a cholera outbreak in Ethiopia's Oromiya region. Disaster Medicine and Public Health Preparedness, 4, 312-317.

Baum, R., Kayser, G., Stauber, C., \& SobseyM. (2014). Assessing the microbial quality of improved drinking water sources: results from the Dominican Republic. The American Journal of Tropical Medicine and Hygiene, 90(1), 121-123.

Dzwairo, B., Hoko, Z., Love, D., \& Guzha, E. (2006). Assessment of the impacts of pit latrines on groundwater quality in rural areas: a case study from Marondera district, Zimbabwe. Physics and Chemistry of the Earth, 31, 779-788.

Ethiopian Standard ES ISO 9308-1:2001. (2001). Water quality detection and enumeration of coliform organisms and presumptive Escherichia coli .1st Edition .part one. Addis Ababa.

Ethiopian Standard ES ISO7899-2:2005 (2005) Water quality detection and enumeration of intestinal enterococci.1st Edition part two. Addis Ababa.
Graham, J. P., \& Polizzotto, M. L. (2013). Pit latrines and their impacts on groundwater quality: a systematic review. Environmental Health Perspectives, 121(5), 521-530.

Godfrey, S., Timo, S. F., \& Smith, M. (2005). Relationship between rainfall and microbiological contamination of shallow groundwater in Northern Mozambiqu. Water S.A., 31(4), 609-614.

Howard, G., Pedley, S., Barrett, M., Nalubega, M., \& Johal, K. (2003a). Risk factors contributing to microbiological contamination of shallow groundwater in Kampala, Uganda. Water Research, 37, 3421-3429.

Howard, G., Ince, M., \& Smith, M. (2003b). Rapid assessment of drinking water quality: a handbook for implementation. Loughborough: WEDC, Loughborough University https://dspace.Iboro.ac.uk/2134/12737.

Luby, S. P., Gupta, S. K., Sheikh, M. A., Johnston, R. B., Ram, P. K., \& Islam, M. S. (2008). Tube well water quality and predictors of contamination in three flood-prone areas in Bangladesh. Applied Microbiology, 105, 1002-1008.

Tabor, M., Kibret, M., \& Abera, B. (2011). Bacteriological and physicochemical quality of drinking water and hygienesanitation practices of the consumers in Bahir Dar city, Ethiopia. Ethiopian Journal of Health Sciences, 21(1), 1026228.

Tadesse, D., Desta, A., Geyid, A., Girma, W., Fisseha, S., \& Schmoll, O. (2010). Rapid assessment of drinking-water quality in the Federal Republic of Ethiopia: country report of the pilot project implementation in 2004-2005. NewYork: World Health Organization, Geneva, United Nations Children's Fund http://www.wssinfo.org/fileadmin/user upload/resources/RADWQ_Ethiopia.pdf.

Tokajian, S., \& Hashwa, F. (2003). Water quality problems associated with intermittent water supply. Water Science and Technology, 47(3), 229-234.

WHO. (2008). Guidelines for drinking-water quality third edition incorporating the first and second addenda (Vol. 1, 3rd ed.). Geneva: Recommendations.

WHO. (2012). Rapid assessment of drinking-water quality: a hand book for implementation. Geneva, Switzerland: World Health Organization.

WHO, \& UNICEF. (2017). Progress on Drinking water, sanitation and hygiene: update and SDG baselines. Geneva: World Health Organization (WHO) and the United Nations Children's Fund (UNICEF) Licence: CC BY-NC-SA 3.0 IGO.

Publisher's note Springer Nature remains neutral with regard to jurisdictional claims in published maps and institutional affiliations. 